\title{
Uso de coprodutos da extração de vermiculita na produção de mudas Piptadenia stipulacea (Benth.) Ducke
}

Maria José de Holanda Leite ${ }^{1}$

Olaf Andreas Bakke ${ }^{2}$

\section{Resumo}

A extração de vermiculita gera coprodutos que são depositados no entorno das indústrias mineradoras, causando problemas ambientais. Este estudo objetivou avaliar a utilização da mistura equitativa dos coprodutos poeira fina e ultrafina da extração da vermiculita e a quantidade necessária de esterco bovino a ser adicionada ao substrato de produção de mudas de Piptadenia stipulacea (Benth.) Ducke. 0 experimento foi conduzido entre abril de 2013 e fevereiro de 2014 no Viveiro Florestal da UAEF/CSTR/UFCG, Patos (PB), Brasil, em um delineamento inteiramente casualizado com 6 tratamentos: solo de baixio com T0=0\% e T1=33\% de EB (v/v), mistura equitativa dos coprodutos da extração de vermiculita com T2=0\%, T3=5\%, T4=10\% e T5=20\% de EB e 5 repetições. As médias de altura, diâmetro basal e massa seca da parte aérea das mudas em CP-vermiculita foram menores do que as verificadas nas mudas se desenvolvendo em solo de baixio sem ou com a adição de EB. Quando o nível de adição de EB aos coprodutos foi de $20 \%$ as médias decresceram, bem como o vigor das rebrotas, pois em três das cinco parcelas deste tratamento as plantas não conseguiram emitir brotações após o corte de sua parte aérea. Caso se opte por utilizar os coprodutos, o nível de esterco bovino deve ficar em torno de 10\%, uma vez que as mudas apresentam vigor suficiente para rebrotar duas vezes e recompor sua altura, diâmetro basal e matéria seca da parte aérea em 90 a 113 dias do corte de sua parte aérea.

Palavras-chave: Atividade mineradora. Áreas degradadas. Matéria orgânica.

\section{Introdução}

A degradação ambiental ocorre principalmente nas regiões áridas, semiáridas e sub-úmidas secas do planeta e resulta de fatores climáticos e antropicostais como as atividades pecuárias, agricultura e mineração, as quais ocorrem principalmente na região semiárida do nordeste do Brasil, que se estende por mais de $980 \mathrm{~km}^{2}$ distribuídos em todos os estados nordestinos (exceto o Maranhão) e no norte de Minas Gerais (ALVES et al., 2009).

O desequilíbrio ambiental é mais crítico no Ceará e na Paraíba, onde a degradação ambiental é observada em mais da metade dos seus territórios. Para esses autores, esta degradação tem um forte componente humano, pois 57,3 milhões de pessoas habitam essa região, além dos 28,2 milhões de bovinos, 7,8 milhões de caprinos e 9,3 milhões de ovinos, que em sua maioria se alimentam da vegetação nativa, caracterizando a região semiárida mais populosa e com maior grau de antropismo no Brasil (LIMA et al., 2015).

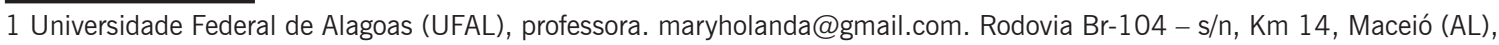
CEP: 57.072-970.

2 Unidade Acadêmica de Engenharia Florestal (UFCG), professor. obakke@cstr.ufcg.edu.br. 
Porém a má utilização desta atividade gera problemas ambientais. A recuperação ambiental é um processo lento e de resultados incertos e demanda ações adequadas às condições ambientais deterioradas, particularmente no que se refere ao solo (KITAMURA et al., 2008; PEREIRA et al., 2013). Uma alternativa consiste na produção e plantio de mudas de espécies arbóreas nativas adaptadas a áreas degradadas, as quais, se produzidas com substratos alternativos em substituição ao substrato convencional, composto basicamente de solo de baixio e esterco, resultariam na não degradação de áreas aluviais e na minimização dos impactos ambientais provocados pela deposição dos coprodutos no entorno das mineradoras (FERREIRA NETO et al., 2007; RODRIGUES et al., 2007).

O substrato para produção de mudas deve ser composto de materiais que proporcionem sustentação e forneçam umidade e nutrientes necessários para o crescimento das mudas (AZEVEDO et al., 2015; PEREIRA et al., 2016). Vários materiais são usados, dependendo da região, segundo Leite et al. (2015), a poeira fina contém P (58 mg dm³); $\mathrm{Mg}\left(3,8 \mathrm{cmol}_{c} \mathrm{dc}^{-3}\right)$ e Ca $\left(14 \mathrm{cmol}_{c} \mathrm{dc}^{-3}\right)$, níveis considerados altos e superiores aos verificados nos solos em geral, com a vantagem de serem disponibilizados gradualmente para a solução do solo.

Entre as espécies arbóreas adaptadas a áreas degradadas, encontra-se a Piptadenia stipulacea (Benth.) Ducke., uma Fabaceae lenhosa da subfamília Mimosoideae que atinge 4 metros de altura e ocorre em áreas de caatinga arbustiva rala do Piauí até a Bahia, em terrenos profundos e bem supridos de água, mas que também se adaptam a terrenos inóspitos e degradados (OLIVEIRA et al., 2009). Esta espécie produz madeira, lenha, remédios, néctar, pólen e forragem e pode ser utilizada na restauração florestal e em sistemas agroflorestais, pois é de rápido crescimento e fixa nitrogênio no solo por meio da simbiose com bactérias noduladoras do gênero Rhizobium (BARBOSA et al., 2013; FARIAS et al., 2013; ALMEIDA et al., 2015).

Este estudo avaliou a utilização da mistura equitativa dos coprodutos poeira fina e ultrafina da extração da vermiculita e a quantidade necessária de esterco bovino a ser adicionada ao substrato de produção de mudas de "jurema branca" Piptadenia stipulacea (Benth.) Ducke.

\section{Material e métodos}

A pesquisa foi conduzida de abril de 2013 a fevereiro de 2014 em ambiente telado localizado no Viveiro Florestal da Unidade Acadêmica de Engenharia Florestal/Centro de Saúde e Tecnologia Rural/Universidade Federal de Campina Grande (UAEF/CSTR/UFCG), Patos (PB), Brasil.

Os substratos testados para a produção de mudas foram: solo de baixio ou mistura equitativa dos coprodutos poeira fina e ultrafina da extração de vermiculita, enriquecidos com esterco bovino em diversas proporções. 0 solo foi coletado de área de baixio a 1,0 m de profundidade, e os coprodutos foram obtidos na Mineradora Pedra Lavrada (MPL), em Santa Luzia, Sertão Paraibano, localizada na Região Nordeste.

O esterco bovino curtido durante 30 dias, o solo de baixio e os coprodutos foram secos, destorroados, homogeneizados, peneirados separadamente em peneira com malha de 2,0 mm e misturados conforme as proporções ditadas pelos tratamentos experimentais. O solo de baixio e os coprodutos foram amostrados e caracterizados quimicamente no Laboratório de Solos da Unidade Acadêmica de Engenharia Florestal do Campus Patos (TABELA 1), seguindo metodologia proposta pela Empresa Brasileira de Pesquisa Agropecuária - EMBRAPA (2006). 
Tabela 1. Atributos do solo de baixio e dos coprodutos da extração da vermiculita (poeira fina e ultrafina) utilizados para a produção de mudas de Piptadenia stipulacea (Benth.) Ducke.

\begin{tabular}{|c|c|c|c|c|c|c|c|c|c|c|}
\hline Substrato & $\mathrm{pH}_{\mathrm{CaCl} 2}$ & $\begin{array}{c}P \\
\mathrm{mg} \cdot \mathrm{dm}^{3}\end{array}$ & $\mathrm{Ca}$ & Mg & K & $\begin{array}{c}\mathrm{Na} \\
\mathrm{cmol}_{c} \mathrm{dm}\end{array}$ & SB & $\mathrm{H}+\mathrm{Al}$ & СTC & $\begin{array}{c}\text { V } \\
----\%\end{array}$ \\
\hline Solo de baixio & 6,2 & 44,1 & 5,0 & 2,4 & 0,18 & 1,68 & 7,26 & 1,1 & 10,4 & 89,4 \\
\hline Poeira fina & 6,4 & 330 & 16,5 & 2,5 & 0,33 & 3,70 & 23,03 & 0,6 & 23,6 & 97,5 \\
\hline Poeira ultrafina & 6,7 & 429 & 26,0 & 4,0 & 0,49 & 6,09 & 36,58 & 0,6 & 37,2 & 98,4 \\
\hline
\end{tabular}

*SB = soma de bases; CTC = capacidade de troca de cátions; $V$ = saturação por bases.

Fonte: Elaborado pelos autores (2014).

Antes da semeadura, as sementes de jurema branca foram colocadas durante vinte segundos em um becker de $100 \mathrm{ml}$ com água fervente após desligamento da fonte de calor e, a seguir, foram resfriadas em água corrente à temperatura ambiente. Após este procedimento, 10 sementes foram semeadas diretamente no substrato de cada vaso com capacidade para $8.000 \mathrm{~cm}^{3}$. Trinta dias após a semeadura (DAS) foi realizado o desbaste, deixando as duas mudas mais vigorosas em cada vaso. Os vasos foram mantidos em ambiente telado entre abril de 2013 e fevereiro de 2014 , com irrigação manual diária.

Dados de altura e diâmetro basal foram coletados aos 37, 41, 44, 58, 65, 72, 86, 100 , 193 e 293 DAS. A altura (cm) foi obtida com régua milimetrada, posicionando-a ao lado da planta e medindo o comprimento entre a superfície do substrato no vaso e a base do meristema apical do fuste (dados coletados até 100 DAS) ou da maior rebrota (dados coletados aos 190 e 293 DAS). 0 diâmetro $(\mathrm{mm})$ foi obtido com paquímetro digital de 0,05 $\mathrm{mm}$ de precisão e correspondeu ao diâmetro da base do eixo caulinar das mudas de jurema branca (dados coletados até 100 DAS) ou à soma dos diâmetros basais de todas as rebrotas das duas plantas de cada vaso (dados coletados aos 190 e 293 DAS).

Cem dias após a semeadura, a parte aérea de cada muda foi cortada, desidratada em estufa de ventilação forçada por $72 \mathrm{~h}$ a $60{ }^{\circ} \mathrm{C}$ e pesada para determinação da massa seca (MS) (g) em balança digital de 0,1 g de precisão. Após este corte, os vasos permaneceram em ambiente telado sob as mesmas condições ambientais e de irrigação já descritas, quando as mudas se recuperaram; as rebrotas foram cortadas novamente aos 190 e 293 DAS.

As parcelas foram aleatorizadas de acordo com um delineamento inteiramente casualizado (DIC) com 6 tratamentos [solo de baixio enriquecido com T0 $=0 \%$ e T1 $=33 \%$ de esterco bovino (EB) e mistura equitativa dos coprodutos poeira fina e ultrafina da extração de vermiculita enriquecidos com $\mathrm{T} 2=0 \%, \mathrm{~T} 3=5 \%, \mathrm{~T} 4=10 \%$ e T5=20\% de $\mathrm{EB}]$ e 5 repetições, totalizando 30 parcelas (vasos com duas plantas).

Os dados de altura, diâmetro basal e MS analisados corresponderam à soma dos valores observados nas duas plantas de cada vaso. Os efeitos de tratamentos foram testados pelo Teste $\mathrm{F}$ da ANOVA e modelos de regressão foram determinados para estimar o efeito da idade e dos níveis de adição de esterco bovino na altura, diâmetro basal e MS da parte aérea das mudas, empregando técnicas de análise de regressão linear para $\mathrm{P}<0,05$. 


\section{Resultados e discussão}

\section{Altura}

A Figura 1 mostra que, no geral, a altura das mudas aumentou de forma significativa no composto solo de baixio com adição de EB, quando comparado aos demais tratamentos de CP-vermiculita. Observa-se que, aos 100 DAS no substrato CP-vermiculita sem adição de EB, este demonstrou baixo crescimento, evidenciando a necessidade de EB na mistura desse tipo de material. As alturas das mudas de jurema branca ficaram entre 21,30 e 120,14 cm/2 mudas, equivalente a 10,65 e $60,07 \mathrm{~cm} \mathrm{muda}^{-1}$, respectivamente. Nesta idade, o substrato de CP-vermiculita com $10 \%$ de EB apresentou altura média de 39,65 cm planta $^{-1}$, comportamento já caracterizado a partir de 72 DAS, porém continuou abaixo dos valores médios observados nas mudas em solo de baixio.

Figura 1. Altura total de duas mudas de Piptadenia stipulacea (Benth.) Ducke em função da idade (de 37 a 100 dias após a semeadura) e da porcentagem (volume) de esterco bovino adicionado aos rejeitos de extração da vermiculita $(0,5,10$ e $20 \%$, volume) e solo de baixio (0 e $33 \%$ )

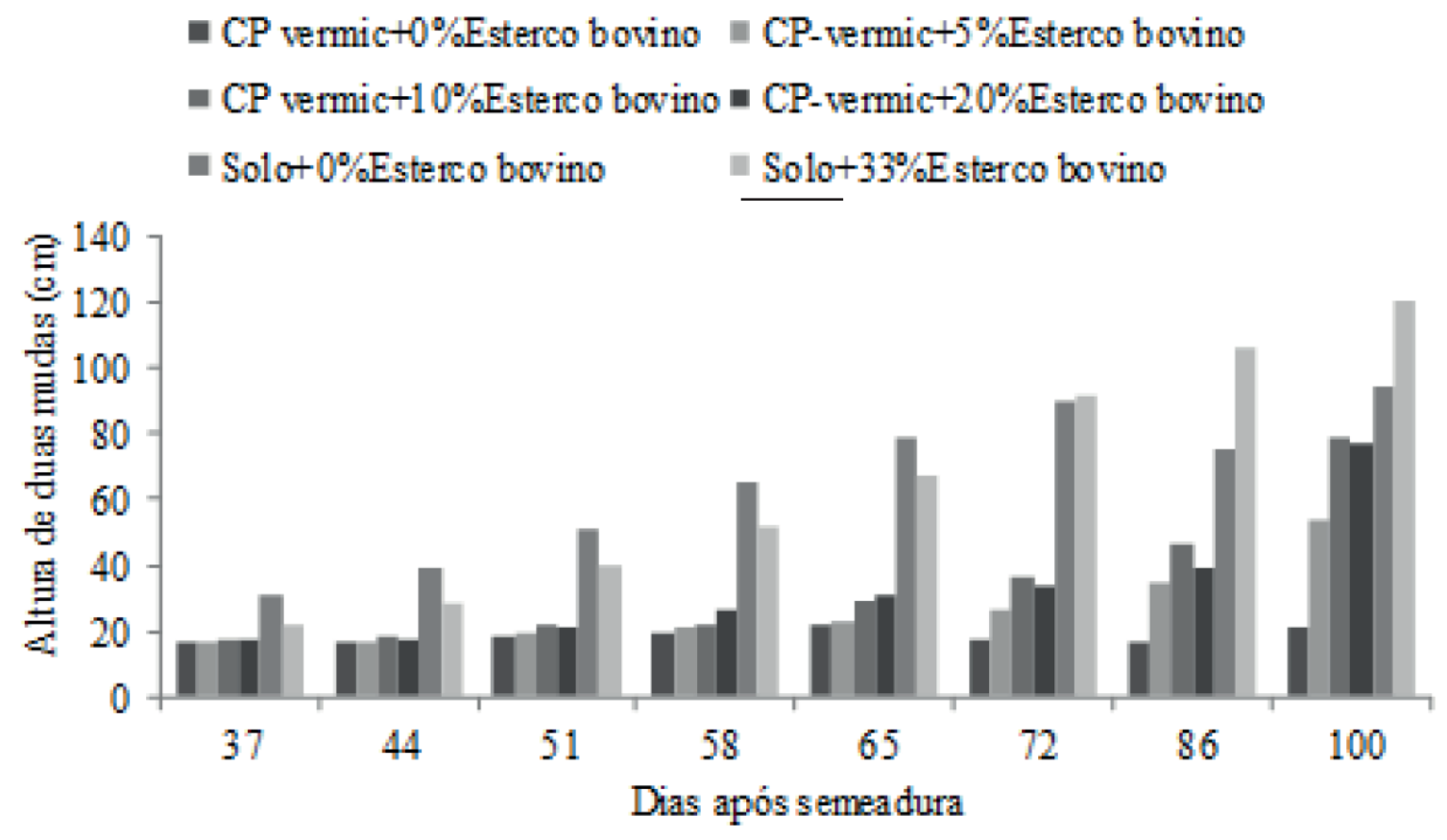

Fonte: Elaborado pelos autores (2014).

Considerando a existência de apenas dois níveis de EB e distantes entre si (0\% e 33\%) e o efeito aparentemente negativo até os 65 DAS, contrastando com o efeito positivo aos 86 e 100 DAS, é possível que exista também entre esses níveis de EB uma dosagem ótima de EB no solo de baixio. Assim, ao utilizar o substrato convencional, pode-se estar desperdiçando EB e ao mesmo tempo produzindo mudas de jurema branca de qualidade aquém da que se poderia atingir. Estudos adicionais são necessários para confirmar esta hipótese.

Os dados do presente estudo foram semelhantes aos reportados por outros autores para a jurema branca. Farias et al. (2013) constataram altura média de 7,1 cm aos 14 DAS para mudas se 
desenvolvendo em substrato composto de fibra de coco, e Barbosa et al. (2013) reportaram altura média de 51,25 cm aos 120 dias após a germinação, utilizando cambissolo no substrato.

Os dados reportados para a altura de mudas de outras espécies arbóreas da Caatinga podem ser interessantes e servir para relativizar o potencial de crescimento da jurema branca. Caron et al. (2007), trabalhando com mudas de aroeira vermelha (Myracrodruon urundeuva Fr. ALL), obtiveram 46,4 cm de altura média, aos 112 dias, em substrato composto de 1/3 de palha de café, 2/3 de latossolo amarelo distrófico corrigido com calcário dolomítico. Bernardino et al. (2006) relataram para mudas de angico vermelho (Anadenanthera macrocarpa Benth.), aos 100 dias após a germinação, altura entre 19,80 e 71,23 cm, utilizando subsolo de três classes de solo no substrato, corrigidos e adubados. Lima et al. (2010) verificaram altura média entre 87,67 cm e 105,00 cm para as mudas de tamboril (Enterolobium contortisiliquum (Vell.) Morong.) e entre 41,67 cm e 54,20 cm para mudas de jatobá (Hymeneae corbari/L. var. stilbocarpa (Hayne) Lee et Lang.) aos 120 dias após a germinação, usando quatro níveis de sombreamentos (0 \%, 30 \%, 50 \% e $80 \%$ ) e substrato comercial Plantmax.

Exceto no tratamento CP-vermiculita com $20 \%$ EB, a jurema branca apresentou um bom poder de rebrota, especialmente no solo de baixio. Nota-se que as rebrotas para cada tratamento são mais altas ao final do segundo corte (190 e $293=113$ dias) do que do primeiro (entre 100 e $190=90$ dias) período de recuperação pós primeiro corte de sua parte aérea efetuado aos 100 DAS (Tabela 2), especialmente no solo de baixio. Este poder de rebrota crescente fica evidente também no tratamento CP-vermiculita sem adição de EB. Nota-se que este tratamento propiciou um crescimento em altura praticamente nulo entre os dias 37 e 100 DAS (FIGURA 1), mas de alguma maneira a rebrota do segundo período conseguiu atingir uma altura média superior à verificada nos primeiros 100 DAS. É como se a planta reagisse de alguma maneira ao corte de sua parte aérea, tal como pela presença de gemas, acúmulo de reservas em seu sistema radicular ou a liberação gradual de nutrientes pelo substrato ao ponto de resultar em rebrotas mais vigorosas que as do período anterior.

Tabela 2. Altura total de duas mudas de Piptadenia stipulacea (Benth.) Ducke (cm/2 mudas) aos 100, 190 e 293 dias após a semeadura (DAS) em função da porcentagem (\%, v) de esterco bovino (EB) adicionado ao substrato (mistura equitativa de coprodutos de vermiculita $=\mathrm{CP}$-vermic e solo de baixio $=$ Solo)

\begin{tabular}{lccc}
\multicolumn{1}{c}{ Tratamentos } & $\mathbf{1}^{\mathbf{0}}$ corte & $\mathbf{2}^{\mathbf{0}}$ corte & $\mathbf{3}^{\mathbf{0}}$ corte \\
& $\mathbf{1 0 0} \mathbf{D A S}$ & $\mathbf{1 9 0} \mathbf{D A S}$ & $\mathbf{2 9 3} \mathbf{\text { DAS }}$ \\
\hline CP-vermic+0\%EB & 21,30 & 11,60 & 29,80 \\
CP-vermic+5\%EB & 53,70 & 59,74 & 131,60 \\
CP-vermic+10\%EB & 79,30 & 121,2 & 138,40 \\
CP-vermic+20\%EB & 77,30 & 37,80 & 29,03 \\
Solo+0\%EB & 94,64 & 159,0 & 301,40 \\
Solo+33\%EB & 120,14 & 174,7 & 274,2 \\
\hline
\end{tabular}

Fonte: Elaborado pelos autores (2014).

Por alguma razão, este acúmulo de reservas ou outro fator qualquer não ocorre no CP-vermiculita enriquecido com 20 \% EB. A mortalidade das plantas após o primeiro corte foi alta neste tratamento (três entre os cinco vasos apresentaram as duas plantas sem rebrota ou mortas, além de um ou dois vasos sem rebrota nos demais tratamentos com CP-vermiculita, ao passo que nenhum vaso com solo de baixio apresentou mudas sem rebrotas). A razão dessa mortalidade merece estudos adi- 
cionais. Assim, não é aconselhável adicionar mais de $10 \%$ de EB aos CP-vermiculita, a não ser que um procedimento adicional corretivo seja efetuado, tal como adição de $\mathrm{N}$ ou $\mathrm{K}$ e que resulte em substrato química e fisicamente balanceado, temas que deveriam ser considerados em estudos adicionais.

\section{Diâmetro}

No geral, o diâmetro das mudas foi menor para os tratamentos com CP-vermiculita, quando comparado aos de solo de baixio entre 37 e 100 DAS (FIGURA 2). Nos tratamentos com CP-vermiculita, o efeito de EB só se mostrou com mais clareza aos 100 DAS, indicando um decréscimo no diâmetro a partir de $10 \%$ de adição de EB. No solo de baixio o efeito se inverteu no período: a princípio se mostrou negativo, invertendo de sentido aos 86 e 100 DAS, porém em um patamar inferior ao esperado de ocorrer, entre 0 e 33 \% de adição de EB. Isso sugere a possibilidade de um ponto máximo entre esses níveis de EB, à semelhança do que ocorreu no substrato CP-vermiculita.

Figura 2. Diâmetro basal total de duas plantas de Piptadenia stipulacea (Benth.) Ducke em função da idade (de 37 a 100 dias após a semeadura) e percentual (volume) de esterco bovino adicionado ao substrato (coprodutos da extração de vermiculita $=$ CP-vermic e solo de baixio $=$ Solo $)$

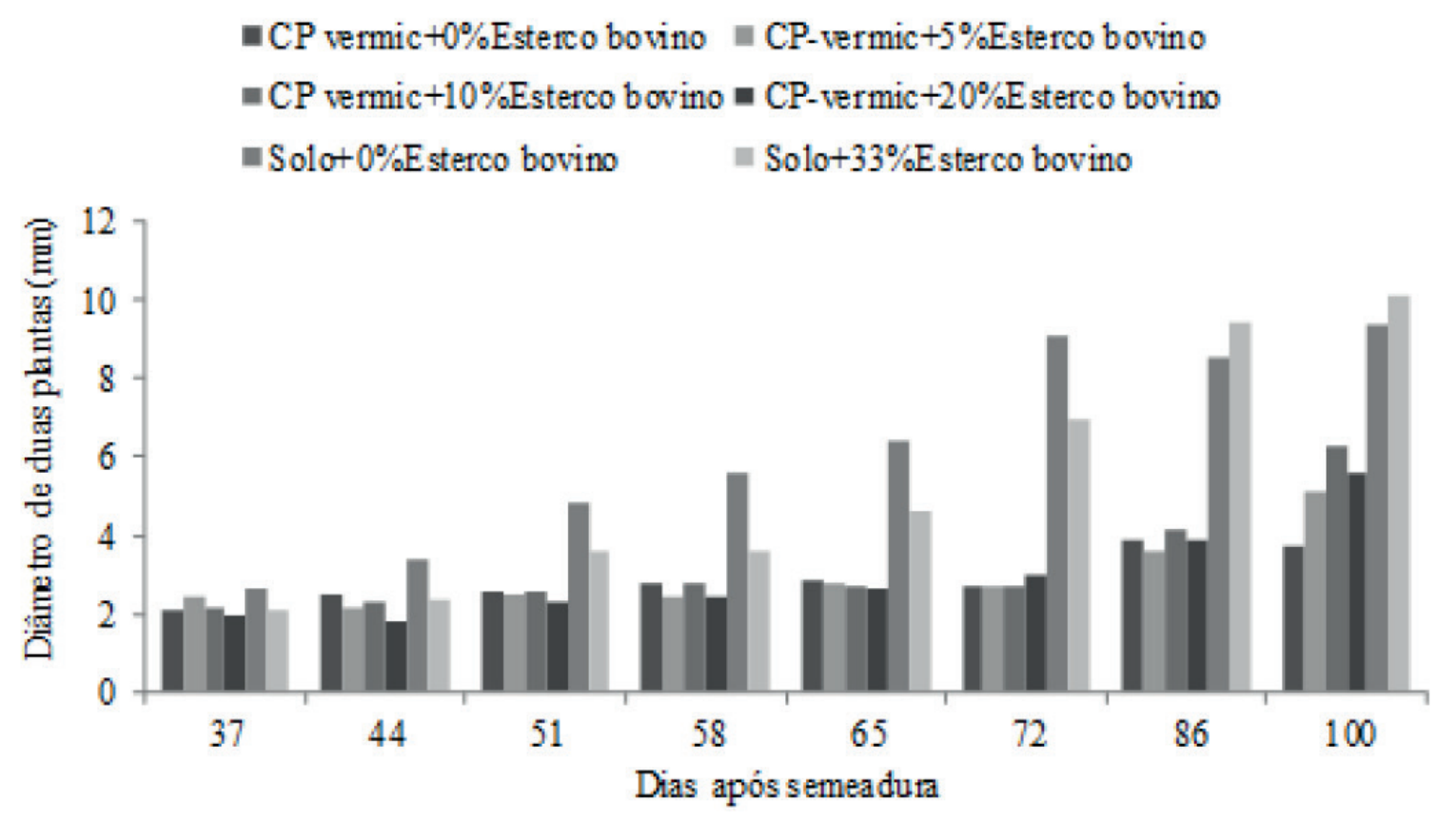

Fonte: Elaborado pelos autores (2014).

Aos 100 DAS, o diâmetro médio das mudas de jurema branca ficou entre 3,74 e 10,13 mm/2 mudas (TABELA 3) ou o equivalente a 1,87 e 5,06 mm muda-1, respectivamente. Para essa idade e para o substrato com CP-vermiculita, a dose de $10 \%$ de EB resultou na maior média $(3,14 \mathrm{~mm}$ planta-1 $^{-1}$, sugerindo a utilização dessa dosagem de EB ao se utilizar o substrato de CP-vermiculita para a produção de mudas de jurema branca. Porém, comparando esse valor com os obtidos no solo de baixio, bem como com os relatados por Barbosa et al. (2013) (6,00 mm) nas condições já relatadas na discussão para altura, tem-se que o CP-vermiculita necessita de outras correções além da adição de $10 \%$ de EB. 
Tabela 3. Diâmetro basal total (mm/2 mudas) de Piptadenia stipulacea (Benth.) Ducke. Aos 100, 190 e 293 dias após a semeadura (DAS)

\begin{tabular}{lccc}
\hline Tratamentos & $\begin{array}{c}\mathbf{1}^{\mathbf{0}} \text { corte } \\
\mathbf{1 0 0} \text { DAS }\end{array}$ & $\begin{array}{c}\mathbf{2}^{\mathbf{0}} \text { corte } \\
\mathbf{1 9 0} \text { DAS }\end{array}$ & $\begin{array}{c}\mathbf{3}^{\mathbf{0}} \text { corte } \\
\mathbf{2 9 3} \text { DAS }\end{array}$ \\
\hline CP vermic+0\%EB & 3,74 & 1,81 & 2,53 \\
CP-vermic +5\% EB & 5,14 & 5,61 & 7,77 \\
CP vermic +10\% EB & 6,28 & 7,55 & 9,39 \\
CP-vermic+20\% EB & 5,60 & 2,58 & 3,47 \\
Solo+0\% EB & 9,35 & 13,13 & 11,47 \\
Solo+33\% EB & 10,13 & 10,59 & 17,40 \\
\hline
\end{tabular}

Fonte: Elaborado pelos autores (2014).

Para o solo de baixio, observando apenas as médias aos 100 DAS, visualiza-se um efeito positivo de EB. Porém, considerando a existência de apenas dois níveis de EB e distantes entre si (0 $\%$ e $33 \%$ ) e o efeito aparentemente negativo até os 65 DAS, contrastando com o positivo aos 86 e 100 DAS (FIGURA 2), é possível que exista também entre esses níveis de EB uma dosagem ótima deste componente no solo de baixio. Assim, ao se utilizar do substrato convencional, pode-se estar desperdiçando EB e ao mesmo tempo produzindo mudas de jurema branca de qualidade aquém da que se poderia atingir. Estudos adicionais são necessários para confirmar esta hipótese.

A jurema branca apresentou um poder de rebrota crescente entre as duas medições das rebrotas (190 e 293 DAS), atingindo, além disto, valores superiores aos verificados nas plantas antes do primeiro corte aos 100 DAS, exceto nos tratamentos CP-vermiculita com 0 ou $20 \%$ EB que resultaram, também, em alta mortalidade, como já relatado anteriormente. Nesses tratamentos, a soma dos diâmetros de todas as rebrotas são maiores ao final do segundo (entre os dias 190 e $293=113$ dias) do que do primeiro (entre 100 e 190 = 90 dias) período de recuperação pós-corte de sua parte aérea (TABELA 3), especialmente no solo de baixio, e superam os respectivos valores observados aos 100 DAS. 0 poder de reação ao corte de sua parte aérea é marcante e, como ressaltado, necessita de estudos adicionais para elucidar como a jurema branca consegue reagir ao estresse provocado pelos sucessivos cortes de sua parte aérea, realizados em períodos de 90 a 113 dias, e esclarecer a razão de isto não ocorrer no substrato CP-vermiculita com 0 ou $20 \%$ de EB.

\section{Massa seca}

Observa-se na Figura 3 que houve efeito de tipo de substrato e de adição de EB na produção total de MS proveniente dos três cortes (planta+rebrota 1+rebrota 2). No geral, o total de MS produzido pelas mudas foi maior no solo de baixio, e o EB afetou positivamente a produção de MS quando adicionado em até $10 \%$ ao CP-vermiculita $(P<0,05)$. 0 enriquecimento dos CP-vermiculita com níveis maiores de EB prejudicou a produção de MS de mudas de jurema branca, causando a mortalidade de um percentual significativo de plantas. 
Figura 3. Massa seca da parte aérea de duas mudas de Piptadenia stipulacea (Benth.) Ducke resultante de três cortes efetuados aos 100, 190 e 293 dias após a semeadura

- Vermic $=$ Solo

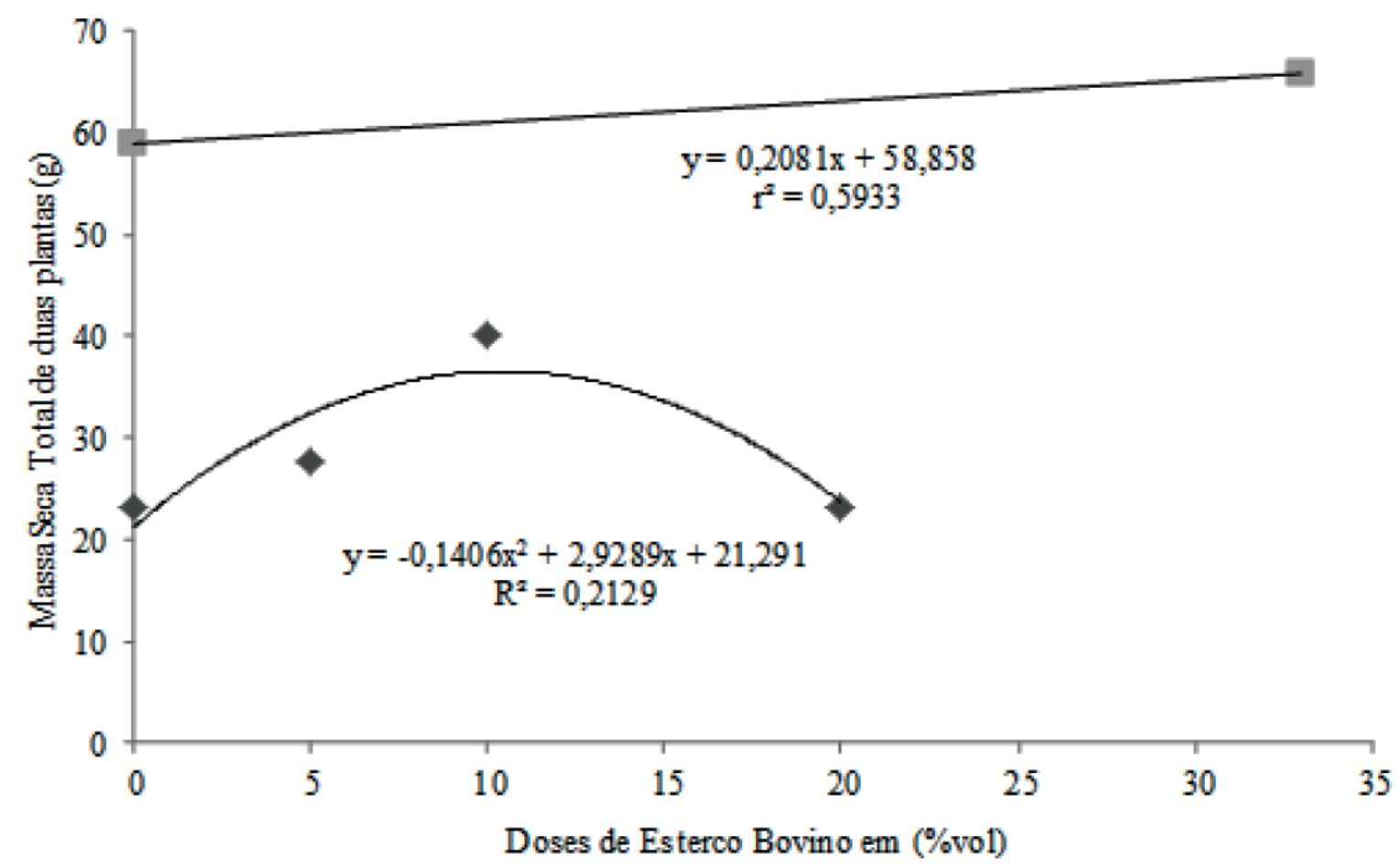

Fonte: Elaborado pelos autores (2014).

O total da MS produzida nos três cortes ficou entre 23,05 e 65,72 g/2 mudas (TABELA 4) ou o equivalente a 11,53 e 32,86 g muda-1 $^{-1}$, respectivamente. Para o substrato com CP-vermiculita, a dose de $10 \%$ de EB resultou na maior média $\left(20,03\right.$ g muda $\left.^{-1}\right)$, o que sugere a utilização desta dosagem de EB ao se utilizar este substrato na produção de mudas de jurema branca. Essa tendência se verificou nas rebrotas coletadas aos 190 e aos 293 DAS. Porém, tem-se que a MS total dos tratamentos com CP-vermiculita chega a no máximo $68 \%$ da verificada nos tratamentos com solo de baixio.

Tabela 4. Massa seca total (g/2 mudas) da parte aérea de duas mudas de Piptadenia stipulacea (Benth.) Ducke resultante dos cortes efetuados aos 100, 190 e 293 dias após a semeadura (DAS)

\begin{tabular}{lcccc}
\hline Tratamentos & $\begin{array}{c}\text { Total dos três } \\
\text { cortes }\end{array}$ & $\begin{array}{c}\mathbf{1}^{\mathbf{0}} \text { corte } \\
\mathbf{1 0 0} \text { DAS }\end{array}$ & $\begin{array}{c}\mathbf{2}^{\mathbf{0}} \text { corte } \\
\mathbf{1 9 0} \text { DAS }\end{array}$ & $\begin{array}{c}\mathbf{3}^{\mathbf{0}} \text { corte } \\
\mathbf{2 9 3} \text { DAS }\end{array}$ \\
\hline CP vermic+0\%EB & 23,05 & 4,54 & 13,22 & 5,29 \\
CP-vermic+5\% EB & 27,72 & 5,65 & 9,35 & 12,72 \\
CP vermic+10\% EB & 40,05 & 7,67 & 14,22 & 18,16 \\
CP-vermic+20\%EB & 23,05 & 8,04 & 4,68 & 10,33 \\
Solo+0\% EB & 58,85 & 15,22 & 18,18 & 25,45 \\
Solo+33\% EB & 65,72 & 16,42 & 14,94 & 34,36 \\
\hline
\end{tabular}

Fonte: Elaborado pelos autores (2014). 
Aos 100 DAS, os valores de MS relativos à massa seca variaram de 4,54 a 16,42 g/2 mudas ou o equivalente a 2,27 e 8,21 g muda $^{-1}$. Esses valores foram inferiores aos reportados por Barbosa et al. (2013), Bernardino et. al. (2005), Caron et al. (2007), Gomes et al. (2012), Lima et al. (2010), nas condições já relatadas: 11,19 g, 14,70 g, 21,52 e 21,27 g, respectivamente. Isso pode ter ocorrido em virtude de a espécie ser adaptada a ambientes degradados, fixar nitrogênio atmosférico e possuir pouca exigência nutricional, não havendo necessidade de adicionar maiores quantidades de esterco bovino ao substrato.

De maneira similar ao observado para a altura e o diâmetro basal, a jurema branca apresentou vigor crescente entre as duas medições das rebrotas (190 e 293 DAS), atingindo, além disto, valores superiores aos verificados nas plantas aos 100 DAS, exceto nos tratamentos CP-vermiculita com 0 ou 20 \% EB nos quais este comportamento não se expressa tão claramente e que resultou, também, em alta mortalidade. Nesses tratamentos, a MS de todas as rebrotas foi maior ao final do segundo (293 DAS) do que do primeiro (190 DAS) período de recuperação pós-corte de sua parte aérea (TABELA 3), especialmente no solo de baixio, e superaram os respectivos valores observados aos 100 DAS. 0 poder de reação ao corte de sua parte aérea foi marcante e merece estudos adicionais para elucidar como a jurema branca consegue reagir ao estresse que deveria ser provocado pelos sucessivos cortes de sua parte aérea realizados em períodos de 90 a 113 dias de recuperação e esclarecer a razão de isto não ocorrer no substrato CP-vermiculita com 0 ou 20 \% de EB.

\title{
Conclusões
}

A produção de jurema branca utilizando a mistura equitativa dos coprodutos poeira fina e ultrafina da extração de vermiculita resulta em mudas menores e com menos massa seca na parte aérea do que as produzidas em substrato solo de baixio com ou sem a adição de esterco bovino.

Caso se utilize esse coproduto na produção de mudas de jurema branca, a adição de esterco bovino não deve ultrapassar os $10 \%$.

\section{Use of coproducts from vermiculite extraction in the production of Piptadenia stipulacea (Benth.) Ducke seedlings}

\begin{abstract}
The extraction of vermiculite generates coproducts that are deposited around mining industries resulting in environmental issues. The aim of this study was to evaluate the use of the equitable combination of fine and ultrafine dust obtained from the extraction of vermiculite, and the necessary amount of cattle manure (CM) added to the substrate to produce Piptadenia stipulacea (Benth.) Ducke seedlings. The experiment was conducted between April 2013 and February 2014, in the tree nursery of the UAEF/CSTR/UFCG, Patos, PB, Brazil, using a completely randomized design with six treatments. The treatments consisted of a lowland soil with $\mathrm{TO}=0 \%$ and $\mathrm{T} 1=33 \%$ of $\mathrm{CM}(\mathrm{v} / \mathrm{v})$ and the equitable combination of the coproducts from the vermiculite extraction with $\mathrm{T} 2=0 \%, \mathrm{~T} 3=5 \%$, $\mathrm{T} 4=10 \%$, and $\mathrm{T} 5=20 \%$ of $\mathrm{CM}$. All treatments were performed with five replicates. The significant values obtained for the height, basal diameter, and shoot dry matter were inferior to those obtained from the seedlings developed in lowland soil, with or without the addition of CM. The average value of sprouting decreased when the level of CM addition to the coproducts was $20 \%$, which was demons-
\end{abstract}


trated by the plants from three of five plots of the treatment being unable to produce sprouts after the shoot was cut. If the preference is for using the coproducts, the level of cattle manure must be of approximately $10 \%$ since the seedlings present enough vigour to sprout twice and restore its height, basal diameter, and shoot dry matter between 90 and 113 days from the cutting.

Keywords: Mining activity. Degraded areas. Organic matter.

\section{Referências}

AlMeIDA, A. M. C.; OLIVEIRA, E.; GALEGARI, L.; MEDEIRAS NETO, P. N.; PIMENTA, A. S. Avaliação físico-química e energética da madeira das espécies Piptadenia stipulacea (Benth.) Ducke e Amburana cearensis (Allemao) A. C. Smith de ocorrência no semiárido nordestino brasileiro. Ciência Florestal, Santa Maria, v. 25, p. 165-173, jan./mar. 2015. Disponível em: http://www.scielo.br/scielo. php?pid=S1980-50982015000100165\&script=sci_abstract\&tlng=pt. Acesso em: 07 jul. 2015.

ALVES, J. J. A.; ARAÚJO, M. A.; NASCIMENTO, S. S. Degradação da Caatinga: uma investigação ecogeográfica. Revista Caatinga, Uberlandia, v. 22, n. 3, p. 126-135, jul./set. 2009. Disponível em: http://www.seer.ufu.br/index.php/caminhosdegeografia/article/view/15740. Acesso em: 01 jan. 2013.

AZEVEDO, W. S. L.; SANTOS JÚNIOR, J. A.; ARAÚJO, A. E.; PEREZ-MARIN, A. M.; MEDEIROS, S. $S$. Organic fertiliser and the use of mulch in cowpea production under semiarid conditions. Revista Ciência Agronômica, Fortaleza, v. 46, n. 4, p. 689-696, out./dez. 2015. Disponível em: http://ccarevista.ufc.br/seer/index.php/ccarevista/article/view/3690. Acesso em: 04 jan. 2016.

BARBOSA, M. L.; SILVA, T. G. F.; SILVA, C. S.; ALMEIDA, M. G.; LIMA, A. L. A.; SOUZA, C. A. A. Crescimento Inicial de Espécies Ocorrentes no Semiárido Brasileiro: Biomassa, Biometria e Análise Morfogênica. Revista Brasileira de Geografia Física, v. 6, n. 3, p. 522-539, 2013. Disponível em: https://periodicos.ufpe.br/revistas/rbgfe/article/view/233059/26980. Acesso em: 02 fev. 2014.

BERNARDINO, D. C. S.; PAIVA, H. N.; NEVES, J. C. L.; GOMES, J. M.; MARQUES, V. B. Crescimento e qualidade de mudas de Anadenanthera macrocarpa (Benth.) Brenan em resposta à saturação por bases do substrato. Revista Árvore, Viçosa (MG), v. 29, n. 6, p. 863-870, 2006. Disponível em: http://www.scielo.br/pdf/rarv/v29n6/a04v29n6. Acesso em: 07 jan. 2014.

CARON, B. O.; MEIRA, W. R.; SCHMIDT, D.; SANTOS FILHO, B. G.; MEDEIROS, S. L. P.; MANFRON, P. A.; MÜLLER, L. Análise de crescimento de plantas de aroeira vermelha no município de Ji-Paraná, RO. Revista da Faculdade de Zootecnia, Veterinária e Agronomia, v. 14, n. 1, p.1-13, 2007. Disponível em: http://revistaseletronicas.pucrs.br/ojs/index.php/fzva/article/view/2474/1933. Acesso em: jun. 2012.

EMPRESA BRASILEIRA DE PESQUISA AGROPECUÁRIA - EMBRAPA. Centro Nacional de Pesquisa de Solos. Manual de métodos de análise de solo. 2. ed., Brasília: Embrapa, 2006. 212p. Disponível em: https://www.infoteca.cnptia.embrapa.br/bitstream/doc/990374/1/ManualdeMtodosdeAnilisedeSolo. pdf. Acesso em: 06 jun. 2013.

FARIAS, R. M.; FREITAS, R.M.O.; NOGUEIRA, N. W.; DOMBROSKI, J. L. D. Superação de dormência em sementes de jurema-branca (Piptadenia stipulacea Benth.). Revista Ciências Agrárias, v. 56, n. 
2, p. 160-165, 2013. Disponível em: https://periodicos.ufra.edu.br/index.php/ajaes/article/download/753/308/. Acesso em: 04 set. 2014.

FERREIRA NETO, M.; HOLANDA, J. S. de; FOLEGATTI, M. V.; GHEYI, H. R.; PEREIRA, W. E.; CAVALCANTE, L. F. Qualidade de fruto de coqueiro anão verde em função de nitrogênio e potássio na fertirrigação. Revista Brasileira de Engenharia Agrícola e Ambiental, Campina Grande, v. 11, n. 5, p. 453-458, 2007. Disponível em: http://www.scielo.br/pdf/rbeaa/v11n5/v11n05a01.pdf. Acesso em: 04 out. 2013.

GOMES, A. D. V.; LEITE, M. J. H.; SANTOS, R. V. Rejeito de vermiculita comparado ao método convencional de viveiros florestais na produção de mudas de sabiá (Mimosa caesalpiniifolia Benth). Revista Verde de Agroecologia e Desenvolvimento Sustentável, Mossoró (RN), v. 7, n. 2, p. 236-241, 2012. Disponível em: https://www.gvaa.com.br/revista/index.php/RVADS/article/download/1261/1257. Acesso em: 01 mar. 2013.

KITAMURA, A. E.; ALVES, M. C.; SUZUKI, L. G. A. S.; GONZALEZ, A. P. Recuperação de um solo degradado com a aplicação de adubos verdes e lodo de esgoto. Revista Brasileira de Ciência do Solo, Viçosa (MG), v. 32, n. 1, p. 405-416, 2008. Disponível em: http://www.scielo.br/pdf/rbcs/ v32n1/38.pdf. Acesso em: 01 jan. 2012.

LEITE, M. J. H.; GOMES, A. V. G.; SANTOS, R. V. Comportamento inicial do maracujazeiro em solos afetados por sais submetidos a tratamentos alternativos com o uso de coprodutos de mineradoras. Irriga, Botucatu, v. 20, n. 3, p. 401-413, 2015. Disponível em: http://irriga.fca.unesp.br/index.php/ irriga/article/view/574. Acesso em: 08 fev. 2016.

LIMA, K. D. R.; CHAER, G. M.; ROWS, J. R. C.; MENDONÇA, V.; RESENDE, A. S. Seleção de espécies arbóreas para revegetação de áreas degradadas por mineração de piçarra na caatinga. Revista Caatinga, v. 28, p. 203-213, 2015. Disponível em: https://periodicos.ufersa.edu.br/index.php/caatinga/article/view/3644. Acesso em: 02 abr. 2016.

LIMA, A. L. S.; ZANELLA, F.; CASTRO, L.D.M. Crescimento de Hymenaea courbaril L. var.stilbocarpa (Hayne) Lee et Lang. E Enterolobium contortisiliquum (Vell.) Morong (Leguminosae) sob diferentes níveis de sombreamento. Acta Amazonica, Manaus, v. 40, n. 1, p. 43-48, 2010. Disponível em: http://www.scielo.br/scielo.php?script=sci_arttext\&pid=S0044-59672010000100006. Acesso em: 02 de mar. 2012.

PEREIRA, P. A. M.; SAMPAIO, S. C.; REIS, R. R.; ROSA, D. M.; CORREA, M. M. Swine farm wastewater and mineral fertilization in corn cultivation. Revista Brasileira de Engenharia Agrícola e Ambiental, Campina Grande, v. 20, n. 1, p. 49-54, 2016. Disponível em: http://www.scielo.br/scielo. php?script=sci_arttext\&pid=S1415-43662016000100049. Acesso em: 20 nov. 2017.

PEREIRA, A. C. C.; AMARAL SOBRINHO, N. M. B.; SAMPAIO JUNIOR, J.; OLIVEIRA, J. A.; SANTOS, F. S.; MAZUR, N. Comportamento da Cordia africana lam. cultivada em solo contaminado por metais pesados e tratado com materiais amenizantes. Ciência Florestal, Santa Maria, v. 23, n. 3. p. 329-336, 2013. Disponível em: http://www.scielo.br/scielo.php?pid =S1980=50982013000300329-\&scriptsci_abstract\&tlng=pt. Acesso em: 23 ago. 2014. 
OLIVEIRA, P. T. B; TROVÃO, D. M. B. M.; CARVAlHO, E. C. D.; SOUZA, B. C.; FERREIRA, L. M. R. Florística e fitossociologia de quatro remanescentes vegetacionais em áreas de serra no cariri paraibano. Revista Caatinga, v. 22, p. 169-178, 2009. Disponível em: https://periodicos.ufersa.edu.br/ index.php/caatinga/article/view/655. Acesso em: 07 dez. 2013.

RODRIGUES, G. B; MALTONI, K. L.; CASSIOLATO, A. M. R. Dinâmica da regeneração do subsolo de áreas degradadas dentro do bioma Cerrado. Revista Brasileira de Engenharia Agrícola e Ambiental, Campina Grande, v. 11, n. 1, p. 73-80, 2007. Disponível em: http://www.scielo.br/scielo.php?pi$\mathrm{d}=$ S1415-43662007000100010\&script=sci_abstract\&tIng=pt. Acesso em: 23 set. 2013.

\section{Histórico editorial:}

Submetido em: 10/04/2017

Aceito em: 12/01/2018 